\title{
Pesquisa socialmente responsável: podemos falar de um Modo 3 de produção de conhecimento?
}

\author{
DOI: $10.3395 /$ reciiis.v2i1.145pt
}

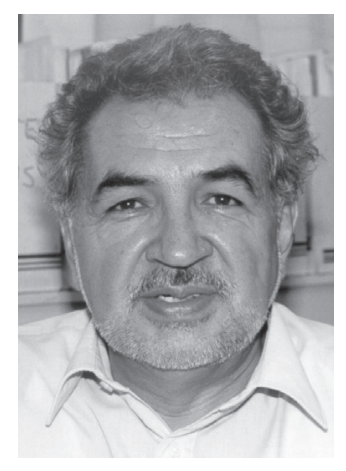

Jaime Jiménez

Instituto de Investigaciones en Matemáticas Aplicadas y en Sistemas, Universidad Nacional Autónoma de México, Cidade do México, México

jjimen@servidor.unam.mx

\section{Resumo}

Um dos efeitos colaterais da globalização da economia é a "globalização da ciência". Parte da produção científica parece estar ligada às necessidades dos mercados globais. Nos últimos 20 anos, surgiram pelo mundo formas alternativas de se "fazer ciência" cuja característica mais importante é sua íntima relação com a solução de problemas de comunidades locais ou regionais. Esse artigo reflete sobre a experiência que está acontecendo atualmente no México, onde a pesquisa está intensamente ligada à função de aprendizagem, e está fortemente enraizada nas Novas Tecnologias de Informação e Comunicação.

\section{Palavras-chave}

Modo 3, produção de conhecimento, responsabilidade social, Comunidades Científicas Regionais, desenvolvimento

\section{Introdução}

Um efeito colateral da globalização da economia é a "globalização da ciência", no sentido de que parte disso trabalha a serviço da economia global. Parte da produção científica parece então, estar conectada às necessidades dos mercados globais. Todavia, nos últimos 20 anos, novas alternativas de "fazer ciência" emergiram por todo o mundo e a característica mais importante é seu íntimo relacionamento com a solução dos problemas percebidos ligados às comunidades locais e regionais. Apesar de dividirem algumas das características da pesquisa "Modo 2", como definido por GIBBONS et al. (1994), diferem drasticamente no sentido de serem socialmente responsá- veis. Essas novas formas são uma resposta à necessidade de tornar a pesquisa científica mais participativa, mais vinculada aos grupos que poderiam afetar seus resultados, incorporando ao processo decisório, não apenas os próprios pesquisadores, mas também aqueles agentes que poderiam ser diretamente afetados por seus produtos. Este artigo reflete sobre a experiência que acontece hoje no México, onde a pesquisa está intensamente ligada à função de aprendizagem, e está fortemente enraizada nas Novas Tecnologias de Informação e Comunicação (NICT). Essa forma de fazer "pesquisa a serviço da humanidade" é consistente com a definição alternativa de desenvolvimento que não está necessariamente ligada ao "crescimento", como tradicionalmente refletidos nas 
estatísticas econômicas. O desenvolvimento não é uma questão do que o indivíduo tem, mas o que é possível fazer com o que tem. O desenvolvimento é a habilidade e desejo de utilizar o que está disponível para melhorar continuamente a qualidade de vida dos indivíduos (ACKOFF, 1974). Projetos como aqueles descritos aqui fornecem um senso de progresso na direção certa, na direção do desenvolvimento verdadeiro. Chamamos essa forma de geração de conhecimento "Modo 3", para diferenciar dos demais modelos de ciência, o Mertoniano (Modo 1) e o de Gibbons (Modo 2). O Modo 3 é um modelo de produção de conhecimento cuja característica distintiva é um compromisso de estar a serviço da humanidade.

\section{O que é desenvolvimento?}

O desenvolvimento é um conceito fácil de ser captado intuitivamente, todavia difícil de ser definido operacionalmente. Na verdade, o termo está associado a nações inteiras ao invés de indivíduos ou organizações. $\mathrm{Na}$ prática, o significado de desenvolvimento e a relevância dos indicadores utilizados pelas agências internacionais, são normalmente tomados por serem óbvios ou auto-evidentes. Os indicadores de desenvolvimento nacionais "medem" certos aspectos da vida dos habitantes que podem estar associados com o "padrão de vida", não necessariamente com qualidade de vida. As agências internacionais como ONU, Unesco, FAO, o Banco Mundial, BID, utilizam indicadores de desenvolvimento tais como PNB per capita, rendimento real per capita, média de escolaridade, expectativa de vida, que são medidas brutas de desenvolvimento, sem qualquer procedimento discriminatório para avaliar como a riqueza, saúde ou educação são distribuídas entre a população. Isso leva ao paradoxo que apesar do México ser a $10^{\mathrm{a}}$ economia mundial (WORLD BANK, 2003), 53,7\% de sua população vive no nível de pobreza (SEDESOL, 2002)

Seria conveniente ter uma definição operacional de desenvolvimento para a construção de uma medida apropriada. Uma vez que não existe tal coisa, os indicadores atualmente em uso são baseados em julgamentos subjetivos. Todavia, uma vez que o consenso entre aqueles que fazem esses julgamentos não é alcançado, não existe um conjunto de indicadores aceitos geralmente.

O caminho para a nação se tornar desenvolvida não é claramente definido. Pode-se escolher uma nação "desenvolvida" como modelo e tentar imitá-la. Mas uma vez que não existe um critério amplamente aceito sobre o que é uma nação desenvolvida, é difícil chegar a um acordo sobre qual modelo seguir. A decisão é tomada por razões políticas e econômicas ao invés de um conceito geralmente aceito do que significa desenvolvimento para nós. Uma questão freqüentemente levantada quando o país está fazendo esforços para selecionar o melhor caminho para o desenvolvimento é a possibilidade de evitar os erros cometidos pelos países desenvolvidos em seus processos de alcançar um padrão de vida mais alto, como altos níveis de poluição, elevada concentração de população ou trânsito em áreas urbanas. A experiência mostra que se deve aprender com seus próprios erros. Apesar dos problemas não serem os mesmos, problemas semelhantes são confrontados por países em processo de desenvolvimento, e as soluções não são necessariamente aquelas adotas pelos países mais avançados. Em conclusão, cada país tem que primeiro definir o que é desenvolvimento para seus habitantes, e depois desenvolver suas próprias maneiras de alcançá-lo.

\section{Desenvolvimento e crescimento}

Como mencionado na introdução, desenvolvimento não deve ser confundido com crescimento, pois não são a mesma coisa. Crescimento é um aumento no tamanho ou número, assim quando o PNB do país aumenta, é correto dizer que sua economia está crescendo. E não dizer que o país está desenvolvendo. Muitas economias emergentes experimentam ambos o processo de crescimento econômico e um aumento no número de desapropriados ao mesmo tempo. Esse fenômeno está acontecendo em muitos países que entusiasticamente fazem parte da economia global, mas mantêm uma distribuição de riquezas desbalanceada. Da mesma forma, uma pessoa pode vivenciar um aumento na riqueza econômica enquanto diminui a sua qualidade de vida, se tornando assim menos desenvolvida. Geralmente o crescimento contínuo da economia do país é considerado desejável, se não necessário, para um desenvolvimento nacional contínuo. Isso não é o caso: a relação entre crescimento e desenvolvimento pode ser entendida apenas quando a natureza do desenvolvimento é compreendida propriamente.

\section{Uma abordagem sistemática para o desenvolvimento}

O conceito de desenvolvimento de Ackoff expresso em Redesigning the Future (ACKOFF, 1974) foi explorado mais profundamente e refinado em escritos subseqüentes. Em A Prolog to National Development Planning (GHARAJEDAGHI et al., 1986, p.18), o desenvolvimento é definido nos termos a seguir:

Desenvolvimento é o processo no qual as pessoas aumentam suas habilidades e desejos de satisfazer suas próprias necessidades e legitimam seus desejos e os [desejos] de terceiros com aquilo que se tem (texto em itálico adicionado).

É mais importante para o propósito do assinante manter a cláusula referente aos meios disponíveis da definição original, uma vez que é o que dá sentido ao desenvolvimento em um país em desenvolvimento. De fato, o principal obstáculo para o desenvolvimento em um país em desenvolvimento é a falta de consciência de sua população de suas capacidades de transformar o mundo ao redor, com os recursos disponíveis, e isso é alcançado quando as pessoas desenvolvem seu próprio futuro e as maneiras de atingi-lo como é o caso da Reflection and Design Conference.

Necessidades são aqueles ítens que são indispensáveis para sobrevivência, como alimentos e oxigênio. O que é necessário pode ou não ser desejado, por exemplo, uma 
pessoa pode necessitar de uma palmilha por conta de problemas de pé chato, mas isso não é algo que deseje. Por outro lado, as pessoas podem desejar coisas que não precisam, como uma viagem para a praia. Um desejo legítimo é aquele "que busca a realização daquilo que não diminui a semelhança da realização de necessidades e (legítimos) desejos de outros. Porém, um aumento na habilidade ou desejo de prejudicar aos outros não é desenvolvimento, mas um aumento na habilidade ou desejo de ajudar é. Isso implica que os esforços para prevenir atos ilegítimos são por si só legítimos" (GHARAJEDAGHI et al., 1986, p.18, ênfase acrescentada).

A definição de Ackoff para desenvolvimento é a mais adequada para sociedades passando por grande escassez material ou, além disso, para se envolver em projetos que poderiam abordar uma melhor qualidade de vida não importando a redução dos meios disponíveis. A realização de projetos baseados nessa definição de desenvolvimento oferece aos participantes um senso de progresso na direção certa.

O que está se passando com o mundo com relação à forma em que a ciência é realizada? Estará caminhando na direção do desenvolvimento de acordo com Ackoff? Quem está recebendo os benefícios da ciência? A ciência é uma despesa apropriadamente alocada? Essa e outras questões foram colocadas nos últimos 10-15 anos. A Unesco tem sido altamente envolvida com o assunto e foi convocada, em 1999, pela conferência mundial, para revisar a direção em que a ciência está seguindo. $\mathrm{Na}$ Conferência chegaram a conclusões muito desafiadoras, que serão discutidas a seguir.

\section{O Novo 'Contrato Social': o espírito de Budapeste}

Por volta do final da década de 1990, o papel da ciência em relação à sociedade e do desenvolvimento estão sendo seriamente avaliados. No passado, a política de ciência era baseada principalmente em atos fé. A crença que a atividade de pesquisa conduziria naturalmente à inovação tecnológica, que por sua vez garantiria o crescimento econômico, e assim coesão social e paz. Acreditava-se com certa ingenuidade que 'o que é bom para a ciência, é bom para a humanidade’, deixando as decisões das políticas de ciência nas mãos dos cientistas.

Atualmente, essa crença tem sido desafiada uma vez que os avanços científicos e tecnológicos que têm contribuído com o desenvolvimento econômico trouxeram também uma deterioração ecológica irreversível, associado à exacerbação da desigualdade social, da exclusão e do aumento nas simetrias entre as nações, em termos e de riqueza e poder.

Os desafios acima motivaram a Unesco a organizar a Conferência Mundial sobre a Ciência: 'a Ciência do Século 21' (UNESCO, 1999, a, b), em Budapeste, em 1999. O objetivo da Conferência era a formulação de um novo relacionamento entre a ciência e a sociedade, que é um novo 'contrato social' (MAYOR, 1999), baseado na suposição de que a ciência está sujeita a escrutínio público. O debate sobre a necessidade de uma discussão democrática sobre as prioridades científicas, o tamanho do orçamento, a estrutura institucional e o uso que é dado aos resultados do trabalho científico está recuperado. Foi declarado que tais decisões não podem simplesmente ser deixadas nas mãos de cientistas e autoridades governamentais.

Na Conferência de Budapeste, a ênfase também foi feita no ponto em que os cientistas não devem orientar suas pesquisas apenas em direção aos tópicos que parecerem ser mais atraentes para subsídio, como as pesquisas militares e pesquisas que respondem às necessidades do mercado, mas também sobre tópicos relacionados ao interesse social em geral. A pesquisa científica não deve ser desenvolvida como disciplina isolada, mas baseada em abordagens inter e transdisciplinares que trarão à tona a convergência entre as ciências natural e social, como formas de entender a realidade, e transformá-la. O que é buscado aqui é confrontar, com maiores possibilidades de sucesso, os desafios que o século 21 apresenta em termos de avanços em direção a uma sociedade com maior liberdade e igualdade entre os homens ao redor do mundo.

Da Conferência de Budapeste é sabido que devemos criar um sistema para o novo contrato social com a ciência, que seja baseado na participação dos maiores setores da sociedade, e não apenas naqueles que atualmente são de interesse. Um novo contrato onde as decisões são tomadas com base em grandes redes sociais. Isso não quer dizer que as formas organizacionais para a tomada de decisão que têm sido aperfeiçoadas durante todo o passado e que, no geral, produziram bons resultados para o avanço da ciência, devam ser desconsideradas.

O objetivo é obter um balanço equilibrado entre a academia autônoma e a responsabilidade social, acesso aos resultados e benefícios produzidos pela ciência e os interesses individuais legítimos daqueles que a promoveram, a redistribuição do conhecimento e dos direitos autorais, crescimento econômico e equilíbrio ecológico, demandas que se originam no mercado e outras fora do mercado, projetos de longo e curto prazo, interesses coletivos e individuais.

A agenda para o novo contrato social com a ciência parece estar complicada. Por um lado não está claro se os cientistas 'hard' estariam dispostos a abrir mão dos privilégios que desfrutam tradicionalmente, compartilhando suas decisões com a sociedade como um todo. Por outro lado, não está claro como os grupos sociais poderiam se envolver de uma maneira informada. A situação ideal é identificar formas que permitam que os pontos discutidos em Budapeste sejam entendidos como tópicos legítimos de interesse público, sujeito a novos mecanismos de tomada de decisão que irão além daqueles que utilizam especialistas nos setores correspondentes. Esse conjunto de idéias constitui o 'Espírito de Budapeste'.

\section{Um novo paradigma proposto para a ciência e a tecnologia}

No final do século 20, os autores observaram que nos anos anteriores, a forma de "produzir conheci- 
mento" havia mudado, e propuseram um novo modelo (GIBBONS et al., 1994). Essa nova forma co-existe com a tradicional e abrange não apenas a ciência e a tecnologia como também as ciências sociais e humanas. Isso afeta:

- que conhecimento é produzido;

- como é produzido;

- o contexto em que é produzido;

- a forma na qual a produção está organizada;

- o sistema de recompensa que é ativado;

- os mecanismos que controlam a qualidade do que é produzido.

Essas características estão firmemente articuladas no caso das ciências "hard": física, química e biologia. De tal modo que as ciências sociais e humanas tentaram imitar as ciências "hard" e foram implementados sistemas sociais semelhantes para governar a produção de conhecimento dessas áreas. Para distingui-los da forma tradicional, os autores denominaram o novo modelo de produção de conhecimento de "Modo 2", e nomearam a forma clássica de "Modo 1 ".

O que se segue são algumas características do Modo 2, no contexto das aplicações:
- problemas não são restritos a disciplina ou grupo de disciplinas (multidisciplinar), que são transdisciplinares;

- o trabalho é realizado de formas não-hierarquizadas, heterogêneas e transitórias;

- sem preferência por institucionalização universitária;

- implicação de interação próxima de muitos atores;

- sob a ótica acima, a produção do conhecimento se torna mais socialmente responsável;

- utiliza uma ampla variedade de critérios para aplicar controles de qualidade;

- o Modo 2 se torna mais flexível e afeta profundamente o que se considera "boa ciência".

Em contraste, o termo "Modo I" se refere a forma de produção de conhecimento - um complexo de idéias, métodos e valores e normas - que está sendo desenvolvido para disseminar o modelo Newtoniano em mais e mais campos de pesquisa e garantir que o que é considerado "estabelecido como prática científica (formal)" seja observado. A Tabela 1 compara as principais características dos dois modelos de produção de conhecimento, de acordo com seus autores.

\section{Tabela 1 - Comparação das características do Modo 1 e do Modo 2 de produção de conhecimento}

\begin{tabular}{c|c}
\hline MODO 1 & MODO 2 \\
\hline $\begin{array}{c}\text { Problemas propostos e resolvidos } \\
\text { por uma comunidade específica } \\
\text { Disciplinar } \\
\text { Homogênea }\end{array}$ & $\begin{array}{c}\text { Problemas propostos e resolvidos } \\
\text { no contexto das aplicações }\end{array}$ \\
Organização hierárquica & Transdisciplinar \\
Permanente & Heterogêneo \\
Controle de qualidade por pares & Organização heterárquica \\
Menos responsável socialmente & Transitória \\
\hline
\end{tabular}

Fonte: GIBBONS et al. (1994).

O modo 2 inclui um grupo maior de "praticantes", que são temporários e heterogêneos, que colaboram em um problema definido em um contexto específico e localizado. De acordo com essa orientação, existe um potencial desequilíbrio entre a volatilidade e a permanência das instituições que cultivam a produção de conhecimento Modo 2. Essa é uma nova situação que aparece como intermediária entre as formas organizacionais estáveis e flexíveis. A produção do conhecimento é uma atividade cada vez menos independente. Não é nem a "ciência" das universidades ou a "tecnologia" da indústria. Os autores declaram que a mudança fundamental no Modo 2 consiste em que a produção do conhecimento é cada vez mais um processo "socialmente distribuído".
Finalmente, o Modo 2, de acordo com seus proponentes, apresentam os seguintes atributos além daqueles apontados na Tabela 1:

- é altamente contextualizado;

- "conhecimento comerciável";

- flexibilidade dos limites disciplinar e institucional;

- carreiras científicas intercambiáveis;

- transdisciplinaridade em tópicos além daqueles considerados "quentes";

- importância crescente de fóruns híbridos na configuração do conhecimento;

- fóruns constituídos por especialistas e não-especialistas como atores sociais. 
Concluindo, no início do século 21, estamos diante de diferentes formas de se fazer ciência, conforme observaram os proponentes do Modo 2 (GIBBONS et al., 1994), todavia essas novas formas disputam em diferentes bases: enquanto alguns (Modo 2) buscam em sua maioria satisfazer as demandas por conhecimento a favor da economia global, o que beneficia poucos, outros são congruentes com “o espírito Budapeste”, e buscam ter a ciência a serviço das comunidades que lhe fornecem apoio, e aspiram a melhor qualidade da vida coletiva. $\mathrm{O}$ que se segue mostra como alguns praticam "o espírito Budapeste".

\section{O Centro para Inovação e Desenvolvi- mento Educacional (CIDE)}

O CIDE deve sua origem aos esforços de um grupo de renomados pesquisadores científicos, com mais de duas décadas de experiência no ambiente educacional, que se conscientizou da necessidade de romper com os métodos tradicionais do ensino superior e pós-graduação, com a criação de novos centros de pesquisa que verdadeiramente responderiam às necessidades regionais. $\mathrm{O}$ resultado final desse esforço é a implementação das redes de pesquisa chamadas "Comunidades Científicas Regionais".

No início, a idéia foi uma iniciativa do Dr. Miguel Arenas, professor da Universidade Autônoma Metropolitana-Xochimilco, na Cidade do México, para colocar em prática o modelo de educação inovativa em diversas universidades mexicanas, com base no reconhecimento de que a demanda de ensino superior nos primeiros 20 anos do século 21 , não seria capaz de ser satisfeita através dos sistemas educacionais tradicionais. O modelo está baseado na metodologia aprendizado com base no proble$m a$, que consiste em reverter o processo pedagógico da transmissão de conhecimento do professor para o aluno, para um processo de criação do conhecimento que inicia com o aluno se confrontando com o problema real, onde o professor age como guia e facilitador do processo de aprendizado. O Dr. Arenas finalmente obteve um acordo com a Universidade de Colima no estado de mesmo nome para ter seu modelo estabelecido lado a lado com o programa tradicional, como uma alternativa de estudo de graduação.

Após um período de 10 anos a Universidade de Colima suspendeu o programa, porém alguns graduandos, já estabelecidos em instituições de ensino superior em outras partes do país, inclusive em Colima, deram continuidade à idéia, e se esforçaram para mantê-la viva. Em 1984, um grupo desses professores da Universidade Autônoma Antonio Narro em Torreón, Coahuila, deram origem ao CIDE, e foram capazes de estabelecer o programa nessa instituição como parte da oferta educacional. Infelizmente, o projeto teve o mesmo destino da Universidade de Colima, e o programa foi fechado definitivamente, apesar de ter sido permitido aos estudantes que já estavam matriculados completar o programa e se graduar naquela instituição.

O CIDE continuou então sua rede virtual de professores preocupados com a falta de oportunidade e acesso a graduação em instituições formais para pessoas incapazes de atender aos programas presenciais. Apenas em 2006 o CIDE finalmente obteve reconhecimento oficial através do Ministro de Educação Pública e Cultura do Estado da Sinaloa, quando se fundiu ao Centro de Estudos Justo Sierra (CEJUS), em um arranjo benéfico para ambas as organizações, ao permitir que o CIDE obtivesse reconhecimento oficial, e ao satisfazer a aspiração CEJUS de estender suas ofertas educacionais ao ensino superior e à pós-graduação.

O CEJUS é outra experiência de inovação na educação que merece menção especial, onde esse autor participou como consultor externo, por mais de 20 anos. O Centro foi criado como resultado das demandas da Associação de Pais local para melhorar a qualidade da educação básica para seus filhos. Nos estágios subseqüentes, a demanda foi ampliada para incluir a pré-escola assim como educação agrícola de nível médio. Em parte, o objetivo era prevenir a dispersão de seus jovens, uma vez que estes eram forçados a deixar suas comunidades para continuar os estudos, na capital do estado. No momento, o Centro hospeda a "Universidade de Mountain Range", oferecendo bacharelado nas disciplinas ligadas a agricultura, e também sedia o programa CIDE. Para maiores informações sobre essa importante experiência educacional, veja JIMÉNEZ (1992), e a própria publicação do CEJUS sobre suas origens (COMITÉ DE PLANEACIÓN EDUCATIVA, 1980).

\section{A metodologia de ensino do CIDE}

O modelo CIDE baseia sua metodologia nos avanços feitos pelas ciências cognitivas, as quais demonstram que o aprendizado é alcançado - especialmente em se tratando de ensino superior e controle de habilidade - quando a ênfase é modificada de ensinar para aprender, baseado nas atividades de aprendizado individuais e em grupo.

Os sistemas consideram as condições de heterogeneidade dos alunos necessária para desenvolver programas não-uniformes, que se adaptam às circunstâncias especiais do indivíduo. Dessa forma, esses modelos garantem a democratização da educação (JIMÉNEZ et al., 2007, p.9), fornecendo ao estudante igual acesso à educação assim como atenção individualizada, liberando a educação de dogmas da pedagogia tradicional para que o estudante seja capaz de seguir um processo individual e desenvolver seu próprio aprendizado, alcançando independência intelectual através do exercício permanente do julgamento crítico.

Dada a contemporaniedade da importância do uso da informação, o princípio fundamental que o método incentiva nos estudantes é a busca e o uso de informações localizadas na fronteira do saber, com o objetivo de garantir que seus projetos e ações de pesquisa sejam solidamente firmados sob dados relatados na literatura especializada atual e altamente visível.

O estudante pesquisa o assunto de seu interesse na internet como uma primeira abordagem para identificar a bibliografia correspondente. Através de poderosos mecanismos de busca, são identificados e selecionados os 
artigos mais recentes, de até cinco anos, sobre o tópico em questão, além daqueles publicados nas mais prestigiosas revistas científicas, conforme ranking da Science Citation Índex, da "Thomson ResearchSoft”, uma divisão da Thomson Scientific. A partir daí, o estudante seleciona uma quantidade de artigos, com atenção especial aos materiais de revisão, uma vez que esses trabalhos fornecem um "estado da arte" da disciplina, uma síntese da pesquisa mais recente e relevante da área de interesse do aluno.

Subseqüentemente, o aluno percebe o que o CIDE denomina "leitura-macro" e "leitura horizontal", que são métodos que oferecem uma maneira de examinar os artigos selecionados, com o objetivo de extrair a informação mais relevante para a pesquisa do estudante. $\mathrm{O}$ aluno também identifica os principais autores no tópico de interesse, notando quem são os autores que são mais freqüentemente citados nos artigos.

O uso das mais avançadas ferramentas da informática para ajudar os alunos em suas atividades de pesquisa é notável. O destaque entre todos é o software chamado EndNote ${ }^{\circledR}{ }^{1}$, um sistema de administração de recursos bibliográficos que acelera consideravelmente a pesquisa e a construção de notas bibliográficas. Com a ajuda desse programa, os alunos têm acesso às maiores base de dados de informação acadêmica, acessada por meios de palavras-chave, autor ou título do artigo.

Além disso, o programa constrói um arquivo de notas bibliográficas para referência futura, um processo que acontece de forma automática. O programa gera uma lista dos autores mais citados em um tópico específico, ou seja, os tópicos de maior relevância científica no momento.

Com o uso dessa tecnologia, os alunos são capazes de identificar os artigos mais relevantes, mesmo aqueles que ainda não foram publicados (artigos que foram aceitos e programados para publicação posteriormente - ahead of print). Como o programa inclui dados pessoais do autor, os alunos do CIDE podem estabelecer contato pessoal com os autores que são líderes em um campo específico de conhecimento ou temática de pesquisa, criando assim sua própria "rede de especialistas". Uma das vantagens desse contato pessoal é a possibilidade de pedir cópias impressas aos autores sem custo. Alguns alunos foram além, colaborando, co-escrevendo artigos com os autores mais renomados de seu campo de estudo.

Para acompanhar os avanços da pesquisa dos participantes, são organizadas sessões de socialização de conhecimento onde os alunos trocam experiência tanto sobre o método de aprendizado como sobre a pesquisa em si. As sessões de socialização de conhecimento são uma das contribuições inovadoras do CIDE, pois, em contraste com outros sistemas baseados no aprendizado, o aluno tem a oportunidade de apresentar seus avanços, lançar dúvidas, propor críticas, não apenas diante de seu tutor, mas dos demais tutores e alunos de diferentes de níveis. Ao mesmo tempo, o aluno recebe o feedback imediato de todos os participantes que desejam contribuir, ou ajudar a solucionar questionamentos importantes, com base em suas próprias experiências e problemas. No final da sessão de contribuição/comentários, o orientador dá sua opinião de especialista assim como sua própria contribuição para o trabalho do aluno, coleta seus avanços, de acordo com um cronograma previamente acordado, e soma as considerações gerais sobre os resultados (JIMÉNEZ et al., 2007, p.11). As observações que os pares fazem são tanto de forma e como de conteúdo. $\mathrm{O}$ relacionamento entre os estudantes é determinado pela existência de algumas habilidades compartilhadas, como o método de coleta de informações, análise bibliográfica, entre outros.

O tutor tem um papel importante na vida acadêmica do estudante. Através de seu aconselhamento, permite que o aluno se torne independente na construção e abordagem do seu objeto de estudo, o tutor se torna um aconselhador ou interlocutor, ajudando o aluno a executar aquelas atividades que permitirão o aprendizado e demonstrarão que ele tem atributos que o qualifica como um Mestre ou Doutor em Ciência. Como parte do processo de avaliação, o tutor certifica a formação do aluno através da validação do resultado do seu programa de trabalho (JIMÉNEZ et al., 2007, p.12). Pode ser observado que o sentimento de pertencimento é forte, uma vez que os participantes expressam terem tido a oportunidade de fazer parte da comunidade científica comprometendo-se com seus objetivos.

A metodologia CIDE traz as propostas mais avançadas que emergem de métodos educacionais inovadores, novos e alternativos, que recentemente foram materializados nos conceitos da educação aberta e educação à distância.

Em resumo, as características definidas de educação aberta e educação à distância com base no modelo de uma das mais prestigiosas instituições da área, a Open University of the United Kingdom, são livres em registro, local de estudo, método e idéias. Provêm oportunidades de aprendizado para todos os indivíduos carentes de recursos econômicos e certificação educacional, aceitando alunos de qualquer classe social ou econômica, e lugar de residência.

Todavia, a educação alternativa deve convencer outras instituições de que sua qualidade é equivalente àquela transmitida pelas instituições tradicionais, em ambientes presenciais. A suposição por trás do descrito acima é que para atingir os objetivos sociais de igualdade no acesso, a educação aberta e à distância trm que ser de alta qualidade. TORRES BARRETO (2006) lista as principais características pedagógico-cognitivas que esses modelos exibem:

1. O sistema deve possibilitar o aluno apontar, interpretar e analisar seus objetivos, no momento inicial assim como durante a sua interação com o programa de instrução.

2. O sistema deve formular os objetivos de aprendizagem para que se tornem a base para a seleção de métodos pedagógicos, incluindo a avaliação, para que seja totalmente compreendido, aceito ou modificado pelos estudantes. 
3. O sistema deve facilitar a participação de todos que quiserem aprender sem impor pré-requisitos tradicionais de admissão e eliminando o grau ou outra certificação como única recompensa a ser obtida pelo estudante.

4. Com o objeto de obter a flexibilidade necesária para satisfazer o amplo espectro das necessidades individuais, o sistema deve permitir o uso efetivo e opcional de som, televisão, filme ou mídia impressa como veículos de aprendizagem.

5. O sistema deve recorrer a atribuições de tarefas e avaliações principalmente para diagnosticar e analisar em que extensão os objetivos do aprendizado foram cumpridos. Em outras palavras, o sistema deve se basear nas próprias competências dos alunos.

6. O sistema deve ser capaz de superar a distância entre a equipe de professores e os alunos, transformando isso em um elemento positivo para o desenvolvimento da autonomia do aprendizado.

Como o mesmo autor relata isso não é apenas mais uma variação das modalidades acadêmicas tradicionais, de uma variante semipresencial, de tipo bi-modal ou de modelo integrado, na qual dentro de um mesmo sistema, alunos presenciais e à distância compartilham os mesmos programas e professores. Um sistema de educação aberto e inovador verdadeiro necessita de estrutura organizacional e administrativa diferente dos modelos presenciais. As Comunidades Científicas Regionais no México praticam exatamente isso, e também, levam o aluno a se concentrar em um objeto de estudo de interesse específico, que é associado com o campo de trabalho onde o aluno está engajado. Assim, a estratégia do CIDE atende a maioria das necessidades sociais imediatas, enfatizando o princípio de participação direta das partes interessadas, incluindo aqueles que recebem os benefícios da ciência, em todos os níveis de decisão.

\section{Comunidades científicas regionais}

O CIDE se constitui de uma comunidade de aprendizado cuja base é a atividade e metodologia científica e o acesso a plataforma tecnológica (Endnote e outras ferramentas da internet) da mais alta ordem possível graças aos avanços na informática e comunicação.

O objetivo do CIDE é formar Comunidades Científicas Regionais. A comunidade é formada com base no grupo de "cérebros" que compartilham um interesse no desenvolvimento científico e colocam todos seus esforços para atingir o objetivo. Geralmente são indivíduos que pertencem a instituições educacionais, centros de pesquisa e, em um pequeno percentual, empresas privadas. Nas palavras de um de seus fundadores: "acima de tudo estamos interessados em gerar 'cérebros' que já estejam envolvidos em atividades profissionais (ensino, pesquisa, análise de laboratório, agricultura, cultivo etc.)" Está claro que essas comunidades não surgem de universidades, mesmo quando estão envolvidas em pesquisa, pois, exibem diferentes objetivos.

Dessas comunidades surgiram os centros de pesquisas regionais virtuais, ou seja, instalações que são negociadas pelos próprios membros do CIDE através de contatos, como laboratórios, para conduzir experimentos conforme necessário para os alunos, salas de reunião para socialização do conhecimento, ou encontros informais. Esse foi o caso na primeira instituição onde o programa foi oferecido, a Universidade de Colima, onde o CIDE pode utilizar o laboratório de Biotecnologia da instituição para produzir importantes resultados científicos que foram posteriormente publicados em revistas científicas internacionais. A seguir está uma lista das Comunidades Científicas Regionais que foram criadas e algumas de suas linhas de pesquisa.

Colima (1982) - A comunidade já produziu em instalações de laboratório mais de 20 teses de doutorado que foram publicadas em revistas científicas internacionais. Os campos de pesquisa são: adaptação a altas temperaturas climáticas e secas, domesticação de vegetais, fertilidade biológica do solo, ecologia de ruminantes, interação planta-patogenia, produção in vitro de células tiróides.

Torreón (1999) - Pesquisa conduzida sobre hipertensão portal de galinhas, uso de cromo na alimentação animal, degradação de paredes celulares por organismos ruminantes, imunologia, dengue, malária, reprodução animal, proteínas de choque calórico, polinização com abelhas.

Sinaloa (2001) - O trabalho é conduzido com fitoremediação e fito-extração de ouro, entono-patogenia de nematóides, biotecnologia aplicada à tuberculose, determinação de custos de produção de dados científicos, bio-sensores, produção de camarão em fazendas, interação planta-patogenia, construção de barragens subterrâneas, re-ordenamento territorial, produção de espécies alternativas, população genética de crocodilos, eco-turismo.

Puebla (2001) - Pesquisa sobre proteínas priônicas, tuberculose.

Nayarit (em processo de formação) - Pesquisa sobre tuberculose, princípios científicos da homeopatia.

O CIDE é um sistema social de características peculiares. Está sendo operado ao longo de 20 a 25 anos, com resultados positivos. Infelizmente, a experiência não foi propriamente documentada, por isso nosso trabalho de "data mining" tem sido torturante. De acordo com López-Pérez (2004), o objetivo do CIDE é a formação das Comunidades Científicas Regionais, e isto tem sido gradualmente atingido. $\mathrm{O}$ mesmo informante declara que 77 indíviduos se graduaram no CIDE com graus de Mestrado e Doutorado. Isso não é, nem pretende ser, a solução para os problemas de alto nível de formação de recursos humanos para o país, todavia é uma alternativa viável para profissionais que necessitam alcançar um grau acadêmico mais alto, mas não podem atender a programas de graduação tradicionais.

O CEJUS se tornou uma ligação coesiva dos diferentes grupos do CIDE distribuídos pelo país. Por outro lado, o CEJUS é um projeto de educação alternativa que compartilha muitas características com o CIDE (JIMÉNEZ, 1992, p.415; JIMÉNEZ et al., 1999, p.171; ZÚÑIGA, 2004). 
Em síntese, a experiência do CIDE demonstra que é possível alcançar os objetivos desejados com o sistema cujas partes desfrutam de ampla flexibilidade, sem a necessidade de uma infra-estrutura física e humana onerosa. A "cola" que une as diferentes partes desse sistema é, certamente, a motivação que cada membro tem para alcançar os seus objetivos pessoais, assim como os objetivos gerais do CIDE.

\section{Modo 3 de produção de conhecimento: pesquisa socialmente responsável}

Como podemos definir o Modo 3 de produção de conhecimento? Esse modelo apresenta algumas das propriedades do Modo 2, porém com a característica distinta de estar proximamente ligado às atuais necessidades sociais. Pode ser discutido que toda a ciência existe em benefício da humanidade. Mas a afirmação é questionável e necessita ser provada. Existem vários exemplos de ciência que direta ou indiretamente prejudica o bem-estar da humanidade.

As Comunidades Científicas Regionais do México são formas inovadoras de criar conhecimento. Paradoxalmente, a propriedade de "responsabilidade social" que aparece no Modo 2 como um aspecto discutível está realmente presente nessas novas formas de se fazer ciência. Além disso, as iniciativas no Modo 3 são ascendentes (de baixo para cima) enquanto no Modo 2 são descendentes (de cima para baixo). A Tabela 2 compara as características mais relevantes dos Modos 2 e 3 .

\section{Tabela 2 - Comparação entre as características do "Modo 2" e do "Modo 3", como observado nas "Comunidades Científicas Regionais" mexicanas}

\begin{tabular}{c|c|c}
\hline PROPRIEDADE & MODO 2 & MODO 3 \\
\hline $\begin{array}{c}\text { Problemas colocados e resolvidos } \\
\text { no contexto das aplicações }\end{array}$ & $\operatorname{Sim}$ & Sim \\
Transdisciplinar & $\operatorname{Sim}$ & Não necessariamente \\
Heterogeneidade & $\operatorname{Sim}$ & Sim \\
Organização heterárquica & $\operatorname{Sim}$ & Não necessariamente \\
Transitória & $\operatorname{Sim}$ & Sim \\
Controle de qualidade realizado \\
por diversos atores \\
Mais socialmente
\end{tabular}

Podemos afirmar que estamos diante de novas formas de se fazer ciência que atende as demandas atuais do contexto social. Por outro lado, o Modo 2 pretende descrever como a ciência está organizada para lidar com as demandas do conhecimento competitivo, pronta para utilizar nos produtos e serviços, em um mundo globalizado economicamente. Por outro lado, as Comunidades Científicas Regionais de fato respondem às necessidades sociais e materiais regionais reais. As Comunidades Científicas Regionais são a resposta para as necessidades e desejos de um segmento da sociedade, implementando formas alternativas de aprendizagem e pesquisa que se adaptam melhor às condições sociais e econômicas do segmento a que serve.

As Comunidades Científicas Regionais respondem, com efeito, às demandas e necessidades da sociedade como um todo, isto é, são responsáveis socialmente. O Modo 2, por outro lado, responde mais prontamente às necessidades do mercado que não necessariamente levam em consideração as necessidades da sociedade.

\section{Conclusões}

As Comunidades Científicas Regionais do México são apenas um exemplo Latino-americano de novas formas de se fazer pesquisa. Os cientistas do CIDE se remetem a forma de organização da aprendizagem e pesquisa semelhante àquela praticada por eles acontecendo na Finlândia, um país escandinavo com cultura e costumes bem diferentes. Por outro lado, as novas formas de interação entre ciência, tecnologia e sociedade em que se baseiam o trabalho das pessoas juntamente com cientistas para produzir e difundir o conhecimento, foram desenvolvidos na França. O termo "pesquisa na loucura" foi elaborado para se referir a esse novo fenômeno (CALLON et al., 2003). Esses autores descrevem a organização dos parentes de pacientes com distrofias musculares, para coletar informação sobre a geração e desenvolvimento dessa terrível doença. Os parentes discutem os achados com especialistas, se envolvendo em um novo tipo de interação onde os cidadãos contribuem para o conhecimento de uma doença de tal com- 
plexidade que vai além da capacidade dos especialistas para obter um melhor entendimento da mesma. Nesse caso, os grupos interessados mostram a forma como as pesquisas devem ser conduzidas, demandando até mesmo os especialistas para explorar as linhas de pesquisa descobertas por eles.

Concluindo, na alvorada do século 21, estamos diante de novas formas de se fazer ciência como observado pelos proponentes do Modo 2, e no Modo 3 como mostrado neste artigo. Essas novas formas atuam em diferentes frentes: alguns (Modo 2) buscam satisfazer as demandas por conhecimento para beneficiar a economia globalizada, servindo aos interesses de poucos. Outros (Modo 3), como as Comunidades Científicas Regionais, são congruentes com o "espírito de Budapeste", e objetivam a ciência para estar a serviço daqueles que a sustentam, servindo aos interesses de muitos, e resultando em uma melhor qualidade de vida coletiva. O principal ponto do Modo 3 é a busca por solucionar os problemas sentidos de uma comunidade específica, sendo na verdade mais socialmente responsável do que o Modo 2.

\section{Agradecimentos}

A Juan Carlos Escalante e Marcelo Ramírez pelas discussões sobre o conteúdo desse artigo durante sua concepção, além de sua contribuição na revisão das tabelas e a compilação de referências.

\section{Referências bibliográficas}

ACKOFF, R.L. Redesigning the future: a systems approach to societal problems. New York: John Wiley \& Sons, 1974.

CALLON, M. et al. Research "in the wild" and the shaping of new social identities. Technology in Society, v.25, n.2, p.193-204, 2003.

COMITÉ DE PLANEACIÓN EDUCATIVA. Autodesarrollo comunitario: alternativa para el medio rural. proyecto experimental educativo. Surutato: Comité de Planeación Educativa, 1980.

GHARAJEDAGHI, J. et al. A prologue to national development planning. Westport: Greenwood Publishing Group, 1986.

GIBBONS, M. et al. The new production of knowledge: the dynamics of science and research in contemporary societies. London: Sage Publications Ltd, 1994.

JIMÉNEZ, J. Surutato: an experience in Rural Participative Planning. In: CHOUKROUN, J.M.; SNOW, R.M.
(Eds.). Planning for human systems: essays in honor of Russell L. Ackoff, Philadelphia: University of Pennsylvania Press, 1992. p.407-416.

JIMÉNEZ, J. et al. Community Development Through Participative Planning. A Conference to Celebrate the Work of Russell L. Ackoff on his 80th Birthday and Developments in Systems Theory and Practice, March 4-6, 1999, Villanova, PA. Proceedings of the Russell L. Ackoff and the Advent of Systems Thinking. Villanova University, p. 167-178.

JIMÉNEZ, J. et al. algunas respuestas alternativas en américa latina a la globalización de la investigación científica. In: ARGENTINE CONGRESO OF SOCIAL STUDIES OF SCIENCE AND TECHNOLOGY) 1., 2007. CONGRESO ARGENTINO DE ESTUDIOS SOCIALES DE LA CIENCIA Y LA TECNOLOGÍA. INTERNACIONALIZACIÓN DE ACTIVIDADES CIENTÍFICAS Y TECNOLÓGICAS, 1., 5-6 jul. 2007, Buenos Aires. Proceedings... Universidad Nacional de Quilmes, CD 1-20.

LÓPEZ-PÉREZ, J. Personal communication via e-mail. Date: Jan. 8, 2004. Address: jolopez@uas.uasnet.mx

MAYOR, F. Message: a new contract between science and society, 1999. At: <www.unesco.org/bpi/science/content/press/anglo/print.htm>. Accessed: April 2, 2008.

SEDESOL. Medición de la pobreza, variantes metodológicas y estimación preliminar. Mexico City: SEDESOL, 2002.

TORRES BARRETO, A. Necesidad de reforma universitaria y educación abierta y a distancia. 2006. Available at: www.unidad094.upn.mx/revista/39/reforma. htm. Accessed: Mar. 7, 2006.

WORLD BANK. Basic Development Indexes, 2003.

UNESCO. Declaration on science and the uses of scientific knowledge. In: WORLD CONFERENCE ON SCIENCE, 1999a. Available at: <www.unesco.org/science/wcs /eng/declaration-e.htm>. Accessed: Aug. 28, 2006.

UNESCO. Science agenda-framework for action. In: WORLD CONFERENCE ON SCIENCE, 1999b, Budapest. paragraph 38, Available at: <www.unesco. org/science/wcs/eng/framework.htm>. Accessed: Aug. 28, 2006.

ZÚÑIGA BARRÓN, S. Pedagogía CEJUS: algunos aspectos didácticos en su construcción y fortalecimiento. Tradición y Costumbres. Culiacán: Private print, 2004 . 


\section{Sobre o autor}

\section{Jaime Jiménez}

Estudou Física no Universidade Nacional Autônoma do Mexico (UNAM) e seguiu a carreira de pesquisador em Ciências Espaciais na mesma instituição. Seu interesse em sistemas no seu sentido mais amplo o levou a fazer um doutorado sob a direção de Russell L. Ackoff e Eric Trist na Wharton School da Universidade da Pennsylvania. É pesquisador em período integral para o Institute of Applied Mathematics and Systems (IIMAS), UNAM, desde 1972. É fundador e chefe do Departamento de Modelos Matemáticos dos Sistemas Sociais na IIMAS. Atualmente, está envolvido em pesquisa de sistemas de ciência e tecnologia, educação e saúde. Além disso, ele é especializado em processo de desenvolvimento, planejamento estratégico participativo, qualidade de vida profissional, qualidade total e grupo dinâmico associado a mudança organizacional. Desenvolvou e utilizou extensivamente a modalidade de Emery and Trist's Search Conference, chamada de Reflection and Design Conference, como uma ferramenta para iniciar os processos robustos do planejamento estratégico participativo. Conduziu projetos de pesquisa para a UNESCO, OIT e agências públicas mexicanas. É editor do Newsletter em C\&T e editor-associado de "Science Studies". É o atual presidente da International Sociological Association, Research Committee 23: Sociology of Science and Technology. Publicou vários livros e artigos em revistas científicas especializadas. Em termos de posições administrativas, foi chefe de departamento e secretário acadêmico na IIMAS. Atualmente conduz um seminário de doutorado em planejamento na UNAM. Desde o início dos anos 1980, é consultor de organizações públicas e privadas, nacionais e internacionais. 